\title{
The anatomy of uppermost mantle shear-wave speed anomalies in the western U.S. from surface-wave amplification
}

\author{
Lewis Schardong, $^{\mathrm{a}, \mathrm{b}, *}$, Ana M.G. Ferreira ${ }^{\mathrm{c}, \mathrm{a}}$, Andrea Berbellini ${ }^{\mathrm{a}, \mathrm{d}}$, William \\ Sturgeon $^{\mathrm{a}}$ \\ ${ }^{a}$ Department of Earth Sciences, University College London, London WC1E 6BT, UK \\ ${ }^{b}$ Now at Department of Geophysics, Tel Aviv University, Ramat Aviv, Tel Aviv 69978, \\ Israel \\ ${ }^{c}$ CERIS, Instituto Superior Técnico, Universidade de Lisboa, Av. Rovisco Pais 1, \\ 1049-001 Lisboa, Portugal \\ ${ }^{d}$ Now at Istituto Nazionale di Geofisica e Vulcanologia - Sezione di Bologna, Via Donato \\ Creti 12, 40128, Bologna, Italy
}

\begin{abstract}
We build SWUS-amp, a three-dimensional shear-wave speed model of the uppermost mantle of the western U.S. using Rayleigh wave amplification measurements in the period range of 35-125 s from teleseismic earthquakes. This represents the first-ever attempt to invert for velocity structures using Rayleigh wave amplification data alone. We use over 350,000 Rayleigh wave amplitude measurements, which are inverted using a Monte Carlo technique including uncertainty quantification. Being a local seismic observable, Rayleigh wave amplification is little affected by path-averaged effects and in principle has stronger depth resolution than classical seismic observables, such as surface wave dispersion data. SWUS-amp confirms shallow mantle heterogeneities found in previous models. In the top $100 \mathrm{~km}$ of the mantle, we observe low-velocity anomalies associated with Yellowstone and the Basin \& Range province, as well as a fast-velocity anomaly underneath the Colorado
\end{abstract}

\footnotetext{
${ }^{*}$ Corresponding author

Email address: lschardong@tauex.tau.ac.il (Lewis Schardong)
} 
Plateau, where a strong velocity gradient at its edges shows a drastic contrast with its surroundings. SWUS-amp also gives additional insights into the current state of the uppermost mantle in the region. We image a high-velocity anomaly beneath the high-topography Wyoming province with a maximum depth extent of about $150-170 \mathrm{~km}$, which is shallower than in previous tomographic models, and resolves previous inconsistencies with geological information. Beneath the Snake River Plain, a finger-like low-velocity anomaly dips to the west, suggesting lateral flow in the region. Below about 150 km depth, SWUS-amp shows a north-south dichotomy in shear-wave speed structure, with the northern region showing mostly high-velocity anomalies, whereas the southern region shows low-velocity anomalies. This is consistent with the continuous subduction history of the western U.S. and with the recent extension and uplift of the southern region.

Keywords: western U.S., surface wave, amplitude, USArray, upper mantle, subduction, extension

\section{Introduction}

The actively deforming, elevated western United States (Fig. 1) shows evidence of a wide range of geological and geodynamical processes. It is one of Earth's significant plateaus and it displays many unique features, such as one of the youngest subducting plates - the Cascadia subduction zone and some of the lowest seismic wave speeds in the Earth's upper mantle. A major control of the tectonic and magmatic evolution of the western U.S. is the progressive eastward subduction of the Farallon plate that initiated $>150$ Ma (for a review see, e.g., Humphreys and Coblentz, 2007). Flat subduction $\sim 40-70 \mathrm{Ma}$ is thought to be responsible for the Laramide orogeny, leading for example to the broad, elevated central Rocky Mountains range (RM in Fig. 1; 
Humphreys and Coblentz, 2007). Geological studies show that the western U.S. is currently undergoing post-Laramide orogenic collapse and associated volcanism (e.g., Burchfiel et al., 1992). In the westernmost part of the U.S., the young ( $10 \mathrm{Ma})$ Juan de Fuca plate plunges into the Cascadia subduction zone and is thought to be a remnant of the Farallon slab (e.g., Humphreys and Coblentz, 2007). To the east, the Columbia Basin (CB in Fig. 1) is a remarkable example of a large igneous province caused by voluminous basaltic volcanism about $17 \mathrm{Ma}$ possibly associated with the Yellowstone hotspot (e.g., Christiansen et al., 2002). Other regions within the interior of the western U.S. that are also marked by recent intense magmatic activity include Yellowstone (YS), the Snake River Plain (SRP), which traces the path of the North American plate over the Yellowstone hotspot, and the Basin \& Range province. The crust and mantle beneath the Basin \& Range province is mostly free of slabs (e.g., Schmandt and Humphreys, 2010). This is thought to be due to the transition of the westernmost North American plate margin from subduction to a transform boundary (Atwater, 1970). Moreover, this transition is also marked by the formation of the San Andreas fault and the rise of the Sierra Nevada (SN in Fig. 1) in California 5 Ma (Atwater, 1970). In contrast, to the east, the Colorado Plateau (CP in Fig. 1) is a single, stable and elevated ( $\sim 1.5 \mathrm{~km}$ high) tectonic block, which possibly remained relatively undeformed in the past $\sim 600$ Ma. Finally, in the northeast of the region lies the Archean-age Wyoming Province (WP in Fig. 1). The WP is part of the core of the Laurentia Craton and may have interacted with a slab - the Cheyenne slab - in its southern edge (Yuan and Dueker, 2005).

With the recent deployment of EarthScope's USArray Transportable Array, great progress has been made towards a better understanding of the past and present dynamical evolution of the western U.S. region. USArray 
data have allowed the construction of increasingly detailed seismic tomographic images mainly based on body wave travel-time and surface wave dispersion data from both earthquakes and seismic ambient noise (e.g., Shen and Ritzwoller, 2016; Porritt et al., 2014; Schmandt and Lin, 2014, to list just a few examples). These images suggest subduction-driven mantle heterogeneity and slab complexity, such as tearing and fragmentation in the Cascadia region (e.g., Humphreys and Hager, 1990). Small-scale convection of the lithosphere has also been suggested, notably in the southern Sierra Nevada and at the edge of the Colorado Plateau (e.g., Zandt et al., 2004; Schmandt and Humphreys, 2010), and in the Wyoming craton (Dave and Li, 2016). In addition, other reported dynamic features include a possible deep mantle plume associated with the Yellowstone hotspot region (e.g., Nelson and Grand, 2018), lithospheric drips, for example in the Colorado Plateau (e.g., Liu et al., 2011) and a possible ongoing mass redistribution at depth related to the present uplift of the Colorado Plateau and Rocky Mountains (e.g., Karlstrom et al., 2008). However, there are still many open questions. For example, the seismic signature of complex subduction of $\sim 5,000 \mathrm{~km}$ of slab in the region in the past $80 \mathrm{Ma}$ is still not fully understood. The nature of the Yellowstone system is still controversial, as well as the origin of the Columbia River large igneous province. Moreover, the architecture of thick, high-velocity lithosphere beneath the high-topography Wyoming and Colorado Plateau is still debated, as well as the nature of small-scale highvelocity anomalies near the Sierra Nevada. Most seismic tomography studies are based on body wave travel-time data and/or surface wave dispersion measurements. A known limitation in such studies is that along-path averaging effects limit the resolution of the images. Using surface wave dispersion measurements via an eikonal approach 
can be one way to reduce such effect (e.g., Shen et al., 2013; Schmandt and Lin, 2014). The near-vertical incidence of body waves also leads to smearing of structure along ray paths, e.g., resulting in artificial vertically elongated structures (e.g., Rawlinson et al., 2010). These limitations hamper a detailed understanding of tectonic processes in complex regions such as the western U.S. Seismic amplitude data offer a great potential to enhance the resolution of tomography images because in principle they are more sensitive to smallscale Earth structure than travel-time or phase data. For example, although surface wave phase is sensitive to the velocity perturbations integrated along the ray path, surface wave amplitudes are sensitive to the second derivative of the velocity anomalies, calculated transversely to the ray (e.g., Ferreira and Woodhouse, 2007; Parisi and Ferreira, 2016). Yet, the observation and modelling of surface wave amplitudes are challenging, as they are affected by elastic and anelastic structure, scattering effects and earthquake source parameters. In addition, their relationship with Earth structure is non-linear (e.g., Ferreira and Woodhouse, 2007). Thus, only few studies have used surface wave amplitude data to map three-dimensional (3-D) mantle structure (e.g., Dalton and Ekström, 2006; Dalton et al., 2017). Here, we address these difficulties by using Rayleigh wave amplification measurements, which tell us how the amplitude of a Rayleigh wave at a given location changes depending on the local crustal and mantle structure (e.g., Eddy and Ekström, 2014; Lin et al., 2012). Being a local-scale observable, surface wave amplification depends mainly on the local elastic, isotropic structure beneath the stations (e.g., Eddy and Ekström, 2014) and is little affected by path-averaged effects. Thus, it is an independent, complementary tool to help unravel geodynamical processes in great detail. Compared with Rayleigh wave dispersion data, amplification has narrower depth-dependent sensitivity kernels (Fig. 
S1), and thus in principle has a stronger depth resolution. The massive amount of high-quality seismograms recorded by the USArray enables us to obtain robust amplification measurements, which are then inverted for local shear-wave velocity $\left(v_{S}\right)$ structure beneath the western U.S.

In this study, we build new images of 3-D shear-wave velocity of the uppermost mantle in the western U.S. using USArray measurements of Rayleigh wave amplification. Previous studies measured Rayleigh wave amplification and showed the potential of the measurements for improving the imaging of crustal and mantle structure (e.g., Eddy and Ekström, 2014; Lin et al., 2012). Here, we go further by performing new amplification measurements and by inverting them for the first time for a 3-D $v_{S}$ model of the uppermost mantle of the western U.S. Our resulting model, SWUS-amp, gives new constraints on the architecture of $v_{S}$ anomalies in the region, which are discussed in terms of its tectonic evolution.

\section{Measuring the local amplification of Rayleigh waves}

\subsection{Seismic data}

We use Rayleigh wave amplitude data anomalies measured using the mode-branch stripping technique of van Heijst and Woodhouse (1997). This amplitude dataset has been recently used in attenuation studies (Bao et al., 2016; Dalton et al., 2017) and includes data from Transportable Array stations deployed between 2004 and 2007 as part of the USArray. From the whole existing amplitude dataset, we focus on fundamental mode Rayleigh waves from 7,744 global earthquakes with M >5.0 from 1991-2007, and recorded at 672 stations located in the western U.S. (Fig. 1). Amplitude anomalies are measured for 18 different dominant wave periods within the 35-275 s period range and are expressed as frequency-dependent ratios $\frac{A(\omega)}{A_{0}(\omega)}$, where 
$A_{0}(\omega)$ is the amplitude of the synthetic waveform calculated for the onedimensional (1-D) reference Earth model PREM (Dziewoński and Anderson, 1981). This results in a total of 373,951 multi-frequency, fundamental mode Rayleigh wave amplitude measurements (Fig. S2).

\subsection{Measurement technique}

The local amplification $A_{R}(\omega)$ at a given receiver $R$ for a vertical-component, fundamental mode Rayleigh wave with angular frequency $\omega$ can be expressed theoretically as (e.g., Ferreira and Woodhouse, 2007):

$$
A_{R}(\omega)=\frac{U(\omega)}{U_{0}(\omega)} \sqrt{\frac{C_{g}^{0}(\omega)}{C_{g}(\omega)}},
$$

where $U(\omega)$ and $U_{0}(\omega)$ are the vertical displacement eigenfunctions evaluated at the receiver location (i.e., at the surface) for the corresponding local 1D structure and for PREM, respectively. $C_{g}(\omega)$ and $C_{g}^{0}(\omega)$ are the group velocities for the same 1-D models.

Local amplification directly contributes to the measured seismic amplitude as $A(\omega)=A_{S}(\omega) \cdot A_{P}(\omega) \cdot A_{R}(\omega)$, where $A_{S}$ and $A_{P}$ are amplitude terms depending on the structure at the source $S$ and along the path $P$, respectively. Considering this relation, Eddy and Ekström (2014) developed a method to measure local amplification by calculating the ratio of surface wave amplitudes, $d_{i j}^{k}(\omega)$, for a given earthquake $k$, and measured at pairs of nearby stations,

$$
d_{i j}^{k}(\omega)=\ln \left(A_{i}(\omega) / A_{j}(\omega)\right)=\ln \left(A_{i}(\omega)\right)-\ln \left(A_{j}(\omega)\right),
$$

where $i$ and $j$ represent the indexes of two nearby stations separated by an inter-station distance of less than $2^{\circ}$. These measurements are performed for a large number of earthquakes with an even azimuthal distribution and are averaged over all the events. This approach allows the elimination of 
contributions from structures at the source $S$ and along the path $P$ (i.e., the $A_{S}(\omega)$ and $A_{P}(\omega)$ terms above), and to isolate the local site amplification at the stations.

In this study we follow a similar approach to that of Eddy and Ekström (2014) with some modifications. For pairs of stations that recorded more than ten common earthquakes, we compute a weighted average of the measurements, which accounts for the azimuthal coverage of the events (Fig. S3):

$$
\bar{d}_{i j}(\omega)=\frac{\sum_{k=1}^{N_{E}} d_{i j}^{k}(\omega) w^{k}}{\sum_{k=1}^{N_{E}} w^{k}},
$$

where $w^{k}=1-n_{E} / N_{E}$ represents the azimuthal weighting coefficient, with $n_{E}$ being the number of earthquakes in a given $15^{\circ}$ azimuthal bin in which the earthquake $k$ is located, and $N_{E}$ being the total number of common earthquakes recorded by stations $i$ and $j$. The corresponding weighted standard deviation is also computed,

$$
\sigma_{i j}(\omega)=\sqrt{\frac{\sum_{k=1}^{N_{E}} w^{k}\left(d_{i j}^{k}(\omega)-\bar{d}_{i j}(\omega)\right)^{2}}{\frac{N_{E}-1}{N_{E}} \sum_{k=1}^{N_{E}} w^{k}}} .
$$

For each pair of stations and for each period of interest, such average inter-station measurements are built from selected single inter-station measurements (see the Supplementary material for more details on the selection criteria used), and constitute the input dataset used to compute local amplification. Fig. S4 shows illustrative examples of inter-station measurements and their weighted averages and errors. Potential biases due to the approach 
used to estimate amplification are reduced by the datas excellent azimuthal coverage and the associated averaging.

Similarly to Eddy and Ekström (2014), we then use the average frequencydependent inter-station measurements to invert for local amplification factors at each station using a least-squares approach minimising the following misfit function:

$$
m^{2}=\sum_{i j} \frac{1}{\sigma_{i j}^{2}}\left[\left(\ln \left(A_{R, i}(\omega)\right)-\ln \left(A_{R, j}(\omega)\right)-\bar{d}_{i j}(\omega)\right]^{2},\right.
$$

where $A_{R, i}(\omega)$ and $A_{R, j}(\omega)$ are the amplification factors at stations $i$ and $j$. In order to overdetermine the inverse problem, Eddy and Ekström (2014) imposed the sum of the amplification factors to vanish across all the stations in the USArray. Given the well-known average low velocity mantle structure in the western U.S., such a constraint is not appropriate to our study region. Thus, instead we impose the sum of the amplification factors to equal the sum of theoretical amplification factors calculated for the 3-D global mantle model SGLOBE-rani (Chang et al., 2015) combined with the global crustal model CRUST2.0 (Bassin et al., 2000), following Eq. (1). In our inversions of Rayleigh wave amplification data for depth-dependent $v_{S}$ profiles (Section 3) we found that the retrieved velocity perturbations did not depend strongly on the imposed sum of amplification factors. On the other hand, the absolute $v_{S}$ values obtained showed a strong dependency on the sum of amplification factors imposed. Fig. S5 illustrates the effect of the amplification sum constraint on the amplification measurements. It is clear that the values of amplification obtained with different amplification sum constraints are different, which would lead to different absolute $v_{S}$ values. Hence, in this study we shall not interpret the absolute velocities determined in the $v_{S}$ inversions but rather the velocity perturbations retrieved. 
Finally, from the uncertainty of the single inter-station measurements, we calculate a diagonal matrix with the errors of the retrieved amplification factors at all stations, $e_{R}$ (Fig. S6), for each period of interest:

$$
\underline{\mathbf{e}}_{R}=\sqrt{\operatorname{diag}\left(\underline{\underline{\mathbf{P}}}^{-1} \cdot \underline{\underline{\mathbf{S}}} \cdot\left(\underline{\underline{\mathbf{P}}}^{-1}\right)^{\top}\right)},
$$

where $\underline{\underline{\mathbf{P}}}$ is the matrix relating $\ln \left(A_{R, i}(\omega)\right)-\ln \left(A_{R, j}(\omega)\right)$ with $\bar{d}_{i j}(\omega)$ and $\underline{\underline{\mathbf{S}}}$ is a diagonal matrix containing the inter-station measurement uncertainties obtained from Eq. (4). We note that this data error definition is different from previous studies (e.g., Eddy and Ekström, 2014; Lin et al., 2012) and hence it is not directly comparable to other studies.

\subsection{Results}

Fig. 2 shows maps of local amplification factors at all available stations, for wave periods of $37.6,51.0,78.2$ and 131.3 s. Fig. 3 shows local amplification curves for eight stations of interest located in each of the eight major tectonic provinces of the western U.S. (Fig. 1). Each observed amplification curve is compared to the theoretical predictions using the 1-D depth profile corresponding to the closest node in the SGLOBE-rani model combined with the crustal model CRUST2.0. Our results are in very good agreement with previous measurements of Rayleigh wave amplification in the same region. At short periods ( $\sim 35 \mathrm{~s})$, highly-amplifying structures are observed along the Cascade and Sierra Nevada ranges, as well as in the vicinity of Yellowstone, and around the northeastern edge of the Colorado Plateau. On the other hand, low local amplification is retrieved at short periods along the Pacific Border and South Basin \& Range, most likely due to the thin crust in those areas (Buehler and Shearer, 2014). At intermediate periods $(\sim 78$ s), high amplification is still imaged underneath Yellowstone and along the Snake River Plain, as well as beneath the North and South Basin \& Range 
provinces. These highly-amplifying features are in clear contrast with lowamplification areas in the northernmost part of the Columbia Basin and in the Rocky Mountains.

When comparing our local amplification maps (Fig. 2) to those determined by Eddy and Ekström (2014) (Fig. S7a-d), we can see that we resolve very similar features. The difference in absolute values, which can be seen by comparing the colour scales of each map (Fig. 2) is due to the use of different constraints on the sum of amplification factors, as explained in Section 2.2 (see also Fig. S5). The correlation between the amplification maps from both studies is very high $(>0.7)$ over all periods considered, as shown in the annotations for each panel in Fig. S7. On the other hand, the correlation with the amplification map at $60 \mathrm{~s}$ of Lin et al. (2012) (Fig. S7e) is lower ( 0.5), which is probably due to the use of different methods in the retrieval of local amplification.

In order to identify outliers, we examined the quality of the single-station measurements and the geographical coherency of the measurements across the various stations. This resulted in the exclusion of $6-9 \%$ of our local amplification estimates, depending on wave period (see Fig. S8 and Section B of the Supplementary material for details of the selection process). Table S1 shows all the detailed, frequency-dependent selection rates and statistics. Based on the response characteristics of the seismic instruments used in our study, we focus on amplification data in the $35-125 \mathrm{~s}$ wave period range in the rest of this paper.

In the Supplementary material (Table S2), we show lists of stations defined as outliers by Shen and Ritzwoller (2016), Eddy and Ekström (2014) and this study. We can see that all three studies identify stations TA. J17A, TA.NO2C and US.MSO as outliers, most likely because of instrumental prob- 
lems. Our study identifies more outlier stations than the studies of Eddy and Ekström (2014); Shen and Ritzwoller (2016) due to the use of stricter selection criteria. Such strict criteria are employed to identify the best possible data for subsequent inversions for velocity structure.

\section{Inverting for local shear-wave velocity structure}

\subsection{Method}

Since Rayleigh wave local amplification is non-linearly related to Earth structure, we use the Neighborhood Algorithm (NA) (Sambridge, 1999) to invert the observed amplification curves for 1-D $v_{S}$ profiles beneath each station of the USArray in the western U.S. The NA is a Monte Carlo approach that samples the model space in a self-adaptative way in order to obtain an ensemble of models that fit the observed data well. Amongst many other applications in the literature, this scheme has been used recently to retrieve the local crustal structure beneath seismic stations from the teleseismic ellipticity of Rayleigh waves (e.g., Attanayake et al., 2017; Berbellini et al., 2017).

The inversion scheme is formed of two main parts: in the first step, the algorithm performs a uniform random search of 2,000 models, and for each of them computes the misfit between the observed and predicted amplification curves. In the second step, the algorithm refines the search by picking 20 random models in the neighborhood of the best five models sampled. The algorithm proceeds iteratively for a total of 200 iterations, every time resampling the model space around the best five models found in the previous iteration. As a result, the inversion scheme produces an ensemble of models and their corresponding data misfits. We tested various numbers of models searched and total numbers of iterations, and found that these parameters 
led to stable results while ensuring that the inversions are computationally efficient.

For each station, we calculate the misfit between observed and predicted amplification using a $L_{2}$-norm misfit function:

$$
s=\sum_{i=1}^{N} \frac{\left[A_{R, i}-g_{i}(\mathbf{m})\right]^{2}}{e_{R, i}^{2}},
$$

where $N$ is the number of wave periods, $A_{R, i}$ are the Rayleigh wave amplification observations obtained in Section $2.3, g_{i}(\mathbf{m})$ is the predicted amplification curve computed from model $\mathbf{m}$ and $e_{R, i}$ is the error associated to each measurement (Eq. (6)).

We compute the predicted curve for each sampled model using Eq. (1), employing a normal mode formulation (Gilbert, 1970). We calculate $P$-wave velocity $\left(v_{P}\right)$ and density $(\rho)$ from $v_{S}$ using scaling relations typically used in tomography (e.g., Chang et al., 2015):

$$
\frac{\delta v_{P}}{v_{P}}=0.5 \frac{\delta v_{S}}{v_{S}}
$$

$$
\frac{\delta \rho}{\rho}=0.4 \frac{\delta v_{S}}{v_{S}},
$$

where the perturbations are with respect to the reference model PREM.

We performed a series of inversion tests to define the model parameterisation used in our inversions. The most stable results were achieved by parameterising $v_{S}$ in the crust using a single flat layer from the surface down to the Moho and $v_{S}$ in the upper mantle using four spline functions (e.g., Chang et al., 2015) from the Moho down to $\sim 300 \mathrm{~km}$ depth. Given the complex sensitivity of local amplification to shear-wave velocity in the crust (Fig. S1), we found that more detailed crustal models, such as two- or three-layer crustal models, require higher frequency data than used in this study. We use Moho depths from the CRUST1.0 global crustal model (Laske et al., 2013). Table 1 
presents the model space for all the parameters considered. The range of parameters searched is smaller for the first spline than for the others to reduce trade-offs between crustal and uppermost mantle structure, while ensuring that the $v_{S}$ values obtained are realistic.

\subsection{Synthetic inversion tests}

In order to test the capability of our inversion scheme to retrieve a realistic input model, we perform synthetic inversion tests. Fig. 4 shows a synthetic inversion test using eight different representative examples of input 1-D Earth models in the western U.S. (Fig. 1), which were obtained from our real data inversions. We simulate 200 predicted amplification curves by adding Gaussian random noise to each point using the standard deviations of real data measurements. Thus, each synthetic amplification curve represents a realistic measurement from a single earthquake. We then compute the average amplification curve and its standard deviation, and use the resulting curve as input synthetic data in the inversion using the scheme described in the previous section. Results in Fig. 4 show that the input $v_{S}$ profiles are overall well recovered. In order to empirically estimate the errors of the retrieved models, we consider the models obtained in the inversions with a misfit within $20 \%$ of the minimum misfit value retrieved in the inversion. While the estimated uncertainties may not include all the errors affecting the results, we tested different misfit thresholds and found that a threshold of $20 \%$ encompasses models that fit the observations reasonably well. Fig. 5 shows that errors estimated with a $50 \%$ threshold are of similar order. Using a stricter threshold seemed too restrictive, potentially leading to loss of information, while more relaxed thresholds led to poor data fits. The error bars shown in Fig. 4 represent these error estimates. They are generally low, but in some cases they can be substantial in the crust and in the uppermost 
mantle, suggesting a trade-off between $v_{S}$ in these two regions (e.g., for station TA.Y14A). Thus, based on these tests, we take the conservative approach of only interpreting structures retrieved below $60 \mathrm{~km}$ depth. Below $\sim 220 \mathrm{~km}$ depth, the retrieval of the input model was poorer due to the weaker sensitivity of the amplification data to that region (Fig. S1). Hence, we do not interpret $v_{S}$ structure obtained below $220 \mathrm{~km}$ depth.

In Fig. S9, we present the results for a synthetic inversion test where the parameterisation of the input model is different from that employed in the inversions. We build an input $v_{S}$ model with two flat layers in the crust and a mantle structure described by 10 spline functions with random coefficients. We then compute the corresponding synthetic amplification curve and add noise using the same approach as described above. Subsequently we invert the obtained synthetic curve using the same parameterisation described in Section 3.1. Results show that the inversion recovers the input model reasonably well below $60 \mathrm{~km}$. The very shallow crust is not well recovered; this is not surprising since shorter period data are needed to resolve that region.

\subsection{Results from real data inversions}

We invert all the available real amplification curves for depth-dependent $v_{S}$ profiles using the method described in Section 3.1. Fig. 5 shows examples of 1-D $v_{S}$ profiles obtained for eight illustrative stations located within the eight major tectonic provinces of the western U.S. For reference, we compare our results with corresponding profiles extracted from the global SGLOBErani model and from the regional tomographic model of Shen et al. (2013). As expected from the synthetic tests in the previous section, the crust and uppermost mantle show the largest uncertainties, but below $60 \mathrm{~km}$ depth our profiles agree generally well with the two previous models presented, especially with the model by Shen et al. (2013). There are nevertheless some 
interesting differences, which will be discussed in the next section. When examining all the station profiles mapped together (Fig. S10), overall we find an excellent geographical coherency between the profiles obtained for the various stations. We estimate the errors in $v_{S}$ using the same approach as described in the previous section. Fig. S11 shows that overall the errors are small, being on average around $\sim 0.25 \%$ at each depth. The errors do not show any clear correlation with geographical location. Moreover, we verify whether there are substantial depth trade-offs in the mantle by plotting all the mantle model parameters explored in the inversions against each other (Fig. S12). As expected, there are some depth trade-offs, but overall the solutions obtained are well clustered around the best-fitting solution (notably those with a misfit within $25 \%$ of the best-fitting model). Hence, depth tradeoffs should not be a main issue.

In order to obtain a new 3-D uppermost mantle model of the western U.S., we interpolate the 1-D depth profiles laterally using an ordinary kriging technique that was successfully used in previous studies of surface wave amplitudes, notably using ellipticity (e.g., Berbellini et al., 2017; Attanayake et al., 2017). We refer to the resulting model as SWUS-amp (first column in Fig. 6); in the next section we discuss its seismic structures and how they compare with other models.

\section{Discussion}

\subsection{Comparison with other models}

Fig. 6 compares constant depth slices of the SWUS-amp model with five other recent tomographic models of the western U.S. In order to enhance the comparison between the various models, we use a different colour scale for each model, but for completeness Fig. S13 presents the same figure with the 
same colour scale for all models. Shen et al. (2013) used a nonlinear Bayesian Monte Carlo method by jointly inverting surface wave dispersion data and receiver functions. Porter et al. (2016) used Rayleigh wave phase velocities calculated using ambient noise tomography and wave gradiometry. Schmandt and Humphreys (2010) built $v_{P}$ and $v_{S}$ models by inverting teleseismic traveltime residuals using frequency-dependent 3-D sensitivity kernels. The model obtained by Schmandt and Lin (2014) is a major expansion of the study of Schmandt and Humphreys (2010), whereby they used a surface wave model of the crust and uppermost mantle as a starting model in their inversions. Finally, Porritt et al. (2014) built the DNA13 model by using teleseismic $P$, $S H$ and $S V$ travel-time measurements, as well as surface wave phase velocity data from both earthquakes and ambient noise.

Many large-scale features in SWUS-amp seem to agree well with those in other 3-D $v_{S}$ models, notably at $60 \mathrm{~km}$ and $100 \mathrm{~km}$ depth. At these depths, all models show clear low-velocity anomalies associated with Yellowstone and the Basin \& Range province. Beneath the Colorado Plateau (CP), there is a clear transition from low- to high-velocity anomalies, with a strong velocity gradient at the edges of the plateau, which was previouly documented (e.g., Schmandt and Humphreys, 2010). Moreover, the models also clearly depict the Wyoming Craton (WC) as a high-velocity anomaly in the easternmost part of the region. Nevertheless, there are some interesting differences between SWUS-amp and other models, notably at depths $>150 \mathrm{~km}$. Below this depth, SWUS-amp shows a north-south dichotomy in $v_{S}$ structure, with the northern region showing mostly high-velocity anomalies, whereas the southern region shows low-velocity anomalies. In contrast, the other models show very similar structures across all the different depths considered. This could be at least partly explained by well-known along-path averaging and verti- 
cal smearing effects that affect tomographic analyses. On the other hand, despite the enhanced depth sensitivity of Rayleigh wave amplification, one has to bear in mind that our model results from the interpolation of 1-D profiles at each station. These profiles reflect the average structure around the station. Maupin (2017) showed that while Rayleigh wave ellipticity has complex sensitivity kernels to $v_{S}$, exhibiting alternating positive and negative values at depth, single-component amplitude kernels are simpler and mostly with the same sign in a confined region around the receiver. This justifies the kriging interpolation carried out in this study. Finally, another distinct feature of SWUS-amp compared to the other models is that overall it displays larger variations in $v_{S}$ anomalies. This is probably due to the fact that we do not use any regularisation in our inversions and may be linked to the local nature of the data used, and that the observable used (local amplification), has a depth sensitivity sharper than e.g. surface-wave dispersion data (see Fig. S1).

In the next sub-sections we examine the $v_{S}$ structure in SWUS-amp in various regions of the western U.S. We analyse in detail cross-sections beneath Yellowstone, the Wyoming province, Cascadia, California, Sierra Nevada, Basin \& Range and the Colorado Plateau. We discuss and interpret our results, and compare them with other models.

\subsection{Yellowstone and the Wyoming Province}

Vertical cross-sections through Yellowstone and the Wyoming Province (WP) give us a good insight into the local $v_{S}$ structure of the mantle beneath the area (Fig. 7). All the profiles show the presence of a large low-velocity feature (YS) beneath Yellowstone from the crust down to at least $100 \mathrm{~km}$ depth and possibly deeper (e.g., profiles BB', CC', DD' and EE'). The anomaly has a lateral extension of $\sim 200 \mathrm{~km}$, following the hotspot track to the southwest 
of the present location of the volcano, along the Snake River Plain (profile CC'). Moreover, profiles AA' and FF' suggest a finger-like, low-velocity anomaly dipping to the north-northwest. The most substantial low-velocity anomalies seem to occur beneath the central Snake River Plain (SRP) rather than directly beneath Yellowstone, which is consistent with results from a recent 3-D electrical conductivity model (Kelbert et al., 2012).

These observations also agree with recent high-resolution images of the Yellowstone magmatic system (Huang et al., 2015), which show that in the shallow mantle the low-velocity anomalies are mostly to the west of the modern Yellowstone volcano. The YS low-velocity anomaly appears the strongest down to $\sim 100 \mathrm{~km}$ depth, possibly due to partial melting. Moreover, the apparent shallow low-velocity signature of Yellowstone and the finger-like anatomy of the anomaly are also consistent with lateral flow in the region (Zhou et al., 2018a) and with a recent model of volcanism in Yellowstone due to intruding oceanic mantle driven by subduction (Zhou et al., 2018b). Nevertheless, since our study is restricted to the uppermost mantle, we cannot exclude that the YS anomaly may also be associated with other low-velocity features in the deeper mantle which may indicate a deep mantle plume source (e.g., Nelson and Grand, 2018).

The Wyoming Province (WP) shows one of the most prominent highvelocity features of SWUS-amp, located in its easternmost part (annotated as "WC" in Fig. 8; see also the location map in Fig. 1). The WP is the western part of the much larger Laurentian craton, whose maximum depth extent was recently refined to $173 \pm 5 \mathrm{~km}$ in a recent study combining SS precursors and xenolith data (Tharimena et al., 2017). This thickness is in good agreement with our observations; for example, profiles CC', EE', FF' in Fig. 8 show that the WC high-velocity anomaly goes down to a depth 
of 150-170 km. On the other hand, previous tomography models (e.g., in Fig. 6) show much thicker high-velocity anomalies down to $\sim 250-300 \mathrm{~km}$ depth, which are difficult to reconcile with the $\sim 1.5 \mathrm{~km}$ uplift of the region (e.g., Schmandt and Humphreys, 2010). Furthermore, in profile FF', the high-velocity anomalies observed at around $100 \mathrm{~km}$ depth underneath the WP may also correspond to a combination of the signature of the Wyoming Craton and of the Cheyenne slab, a fossil slab segment (Yuan and Dueker, 2005; Porritt et al., 2014).

\subsection{The Cascadia subduction zone}

In order to investigate the $v_{S}$ structure beneath the Cascadia subduction zone, which represents the last stage of the great Farallon subduction event, we build cross-sections at constant latitude through the area (Fig. 8). We image the young ( $10 \mathrm{Ma}$ ) subducting Juan de Fuca (JdF) slab from depths greater than $\sim 70 \mathrm{~km}$; at shallower depths there is a relatively weak velocity contrast with the cratonic lithosphere to the east (Porritt et al., 2014). The JdF slab is thought to result from the reinstatement of normal subduction after the accretion of the Siletzia microcontinent, and following a period of flat-slab subduction (e.g., Schmandt and Humphreys, 2010). The slab's fast-velocity signature is rather clear in all the profiles. However, beneath northern Oregon, in profile CC', a low-velocity anomaly appears in the slab region, which is possibly due to a slab window in that region (e.g., Schmandt and Humphreys, 2010; Porritt et al., 2014). Further south, profiles DD' to HH' show increasingly deeper high-velocity anomalies, which are marked by "JdF?" annotations in Fig. 8. These anomalies tend to occur below $150 \mathrm{~km}$ depth, which may reflect the continuous subduction episodes that occurred in the past $80 \mathrm{Ma}$ in the region (e.g., Humphreys and Hager, 1990). Profiles EE' and FF' suggest that the high-velocity anomalies at $\sim 100-150 \mathrm{~km}$ 
depth are disrupted by low-velocity structures, which have been interpreted as interactions between the slab and the Yellowstone plume (Obrebski et al., 2010). Nevertheless, the presence of substantial, predominantly high-velocity anomalies from $\sim 100-150 \mathrm{~km}$ depth in the region suggests that slabs in the northwestern U.S. dominate the mantle flow. Combined with the finger-like low-velocity anomalies beneath the SRP discussed in the previous section, our best interpretation of the Yellowstone system would thus be that it results from subduction-driven volcanism (Zhou et al., 2018b). Yet, it is also possible that thin upwelling structures such as thin mantle plumes that cannot be currently resolved with seismic data could be present below $200 \mathrm{~km}$. Such structures could rise around the slab fragments in the region and feed the low-velocity anomaly beneath Yellowstone. Future research work beyond this study will test this hypothesis. To the west, the dominance of slabs suggests that the Columbia River large igneous province (LIP) may also be due mostly to subduction-related processes, rather than having a deep mantle origin. This could explain why the Columbia River basalt province is the main LIP whose location does not correspond to the margins of the large low-velocity provinces in the lowermost mantle (e.g., Torsvik et al., 2006).

A recent seismic tomography study reported a strong, linear low-velocity anomaly beneath the Juan de Fuca slab along the entire Cascadia subduction zone at $\sim 150 \mathrm{~km}$ depth. This anomaly was proposed to result from the accumulation of material from a thin, weak, buoyant layer present beneath the entire oceanic lithosphere (Hawley et al., 2016). The cross-sections of SWUS-amp in Fig. 8 also suggest such low-velocity features, supporting the idea that a buoyant asthenosphere may be accumulated beneath the lithosphere in this region. 


\subsection{California, Sierra Nevada, Basin 83 Range and the Colorado Plateau}

The vertical cross-sections in Fig. 9 show that the mantle's $v_{S}$ structure beneath the Basin \& Range is most likely characterised by low velocities, all the way down to $200 \mathrm{~km}$ depth (see, e.g., profiles AA' and BB'). This is consistent with other models (e.g., Fig. 6) and could agree with the ongoing history of extension in the region possibly due to the removal of the Farallon slab (e.g., Schmandt and Humphreys, 2010). On the other hand, narrow, small-scale high- and low-velocity anomalies are retrieved beneath California and the Sierra Nevada. Two prominent low-velocity anomalies are depicted at $\sim 100 \mathrm{~km}$ depth in the eastern and southeastern borders of the Sierra Nevada province, beneath the Long Valley Caldera (LVC; profile AA') and the Coso Volcanic Fields (CVF; profile BB'), respectively. These anomalies have also been observed in previous studies and could be due to magmatism and melt in the region (e.g., Jiang et al., 2018, and references therein).

The so-called Great Valley high-velocity anomaly (GV; profile AA') is observed east of the San Francisco Bay in central Sierra Nevada. Compared with the literature, the GV anomaly in SWUS-amp seems to be slightly shifted to the west (e.g., Jiang et al., 2018), and possibly appears in both shallow (top 60-70 km depth) and deeper regions (below $150 \mathrm{~km}$ depth). Another fast velocity anomaly is observed beneath the Transverse Ranges (TR; profile DD'), south of the bend of the San Andreas Fault. Moreover, the Isabella Anomaly (IA; profile BB') is located southeast of the GV anomaly, and, similarly to GV, possibly appears at both shallow $(<60 \mathrm{~km})$ and great (>150 km) depths. This is in contrast with recent reports that show the GV as a shallow anomaly and the IA as a continuous anomaly from $\sim 60$ to 250 km depth. The origin of the IA and GV anomalies has been long-debated. They have been suggested to be either due to a gravitational instability of 
dense lithosphere, or to correspond to a slab fragment from the Monterey microplate, a remnant of the ancient Farallon plate, with the latter explanation gathering increasing evidence (e.g., Jiang et al., 2018). The geometry of the IA in SWUS-amp also suggests that it might represent a slab fragment.

As mentioned previously, SWUS-amp shows that beneath the central part of the relatively undeformed Colorado Plateau $(\mathrm{CP})$ there is a fast $v_{S}$ anomaly at lithospheric depths ( 100 km, noted as "CP" in Fig. 9). This anomaly is separated from the surrounding slow Basin \& Range and Rio Grande Rift provinces by a strong velocity gradient, which is also seen in other tomography models (Fig. 6). This could be consistent with suggestions of lithospheric erosion in the region due to small-scale convection processes (Karlstrom et al., 2008). The westernmost end of the fast CP anomaly seems to be dipping, which could correspond to delamination-style foundering of continental lithosphere as proposed by Levander et al. (2011).

Although the data used in this study do not cover the whole Colorado Plateau, cross-sections AA', BB' and CC' in Fig. 9 show that, for depths larger than $\sim 150 \mathrm{~km}$, the CP high-velocity anomaly transitions to a lowvelocity region. This is in contrast with some previous studies (e.g., Obrebski et al., 2011; Porritt et al., 2014), which reported that the CP fast region is split into two high-velocity bodies in the northwest and southeast edges of the plateau down to at least $200 \mathrm{~km}$ depth (see Fig. 6). The more localised highvelocity anomalies beneath the CP shown in SWUS-amp would be easier to reconcile with the high-topography of the Colorado Plateau than such high-velocity anomalies extending to great depths into the mantle.

\subsection{Future work}

Further quantitative tests would be required to fully assess the differences between SWUS-amp and existing tomographic models of the western U.S. 
One way to do so would be to perform forward modelling of the models using an independent, sophisticated technique (e.g., the spectral element method, Komatitsch and Tromp, 2002) and compare with independent real data. This is well beyond this study and will be the subject of future studies.

Future work will be required to associate in detail the various seismic anomalies imaged in SWUS-amp to specific past tectonic events. Progress in this direction may be achieved by further refining our images using shorterperiod amplification measurements to better constrain crustal and uppermost mantle structures, notably using seismic ambient noise data. Moreover, integrating higher-mode amplitude data to the fundamental-mode dataset should enhance the model's depth resolution. Finally, integrating additional types of data to the analysis, such as surface wave dispersion data, Rayleigh wave ellipticity and receiver functions would also provide further improvements.

\section{Conclusions}

In this study, we build SWUS-amp, the first 3-D model of shear-wave speed in the uppermost mantle based solely on surface wave amplification data. Amplification observations are complementary to classical observables such as surface wave dispersion and body wave travel-time data because: (i) in principle they have stronger depth resolution than, for example, surface wave phase velocity measurements, and (ii) they are a local observable and hence are little affected by along-path averaging and smearing effects. The $v_{S}$ structure in the top $100 \mathrm{~km}$ of SWUS-amp confirms some previously reported features, such as low shear-wave speed anomalies associated with Yellowstone and the Basin \& Range province, and a sharp transition from low to high wave speed anomalies beneath the edges of the Colorado Plateau. SWUSamp also reveals exciting features of the uppermost mantle in the region. 
Beneath the high-topography Wyoming province, we estimate that the highvelocity lithosphere has a thickness of $\sim 150-170 \mathrm{~km}$, which agrees well with geological information, notably xenolith data. This is thinner than $\sim 250-300$ $\mathrm{km}$ thickness estimates from previous tomographic models, which were hard to reconcile with the observed $\sim 1.5 \mathrm{~km}$ uplift of the region. Likewise, SWUSamp shows localised high-velocity anomalies beneath the Colorado Plateau that are more compatible with its high topography than deeper anomalies in some previous tomographic models. Below $150 \mathrm{~km}$ depth, SWUS-amp shows a north-south dichotomy in $v_{S}$ structure. The northern region shows mostly high-velocity anomalies, likely related to the continuous subduction history in the region, whereas the southern region shows mostly low-velocity anomalies, probably related to the recent extension and uplift of the southern region. Beneath the Snake River Plain, SWUS-amp shows a finger-like lowvelocity anomaly dipping to the west, which is consistent with lateral flow in the region, and may be due to intruding oceanic mantle driven by subduction. Thus, we infer that subduction is possibly a key control of the Yellowstone system and of the nearby Columbia River large igneous province.

\section{Acknowledgements}

This research was initially supported by NERC grant NE/K005669/1 followed by NERC grant NE/N011791/1. WS was supported by NERC grant number NE/L002485/1. We thank fruitful scientific discussions supported by the COST Action ES1401-TIDES. We gratefully acknowledge the availability of global seismograms from the IRIS Data Services and the II, IU, GEOSCOPE and GEOFON networks. The seismic data analyses and inversions were carried out on the High Performance Computing Cluster supported by the Research and Computing Support services at University Col- 
${ }_{607}$ lege London and on the national UK supercomputing facility Archer. We ${ }_{608}$ thank Hendrik van Heijst for providing his surface wave amplitude measurements and we thank Jeroen Ritsema and Sung-Joon Chang for fruitful 610 discussions. We thank Weisen Shen for providing his tomography models, as well as Celia Eddy and Fan-Chi Lin for providing their amplification measurements. The other tomography models used in this study were obtained from the IRIS Earth Model Collaboration (http://ds.iris.edu/ ds/products/emc-earthmodels/). The normal mode package used in this 615 study was obtained from the Computational Infrastructure for Geodynamics 616 (https://geodynamics.org/). 

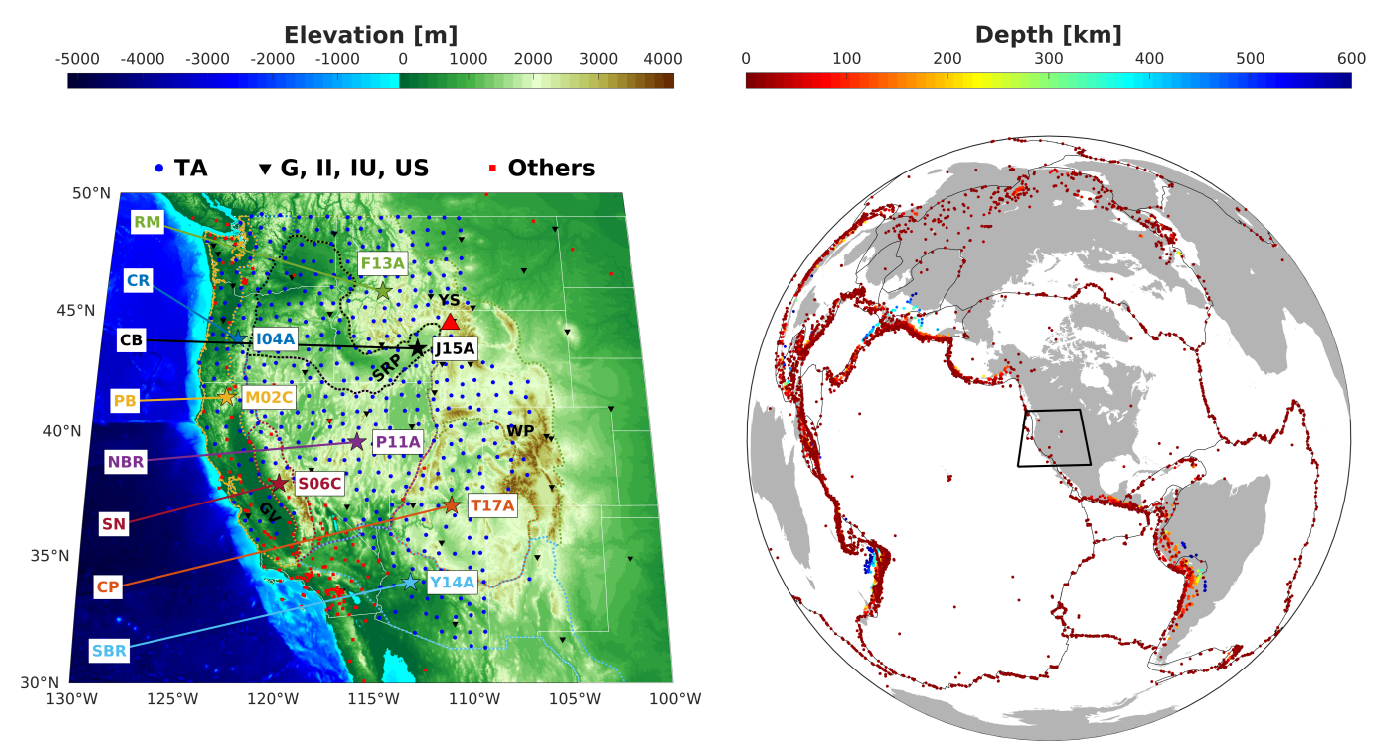

Figure 1: Main tectonic features of the western U.S. (left) and distribution of seismic events used in this study (right). Tectonic provinces are delimited by dotted coloured lines, including the Pacific Border (PB), Cascade Range (CR), Sierra Nevada (SN), Columbia Basin (CB), North Basin \& Range (NBR), South Basin \& Range (SBR), Colorado Plateau (CP), and central Rocky Mountains (RM); locations of the Snake River Plain (SRP), Yellowstone (YS; red triangle), Great Valley (GV) and Wyoming Province (WP) are also indicated. Seismic stations are represented by blue circles, black triangles and red squares, depending on the corresponding seismic network. Labelled stations indicated by stars are illustrative stations used in this study, one in each major tectonic province: TA. M02C in PB, TA. I04A in CR, TA.S06C in SN, TA.P11A in NBR, TA.F13A in RM, TA. J15A in SRP, TA.Y14A in SBR, and TA.T17A in CP. Background colours represent elevation and bathymetry according to ETOPO1 (https://www.ngdc.noaa.gov/mgg/global/). Event locations are extracted from the Global CMT catalog (Ekström et al., 2012), and depths are indicated by the colour of the circles. Boundaries of tectonic plates (Bird, 2003) are indicated by solid black lines. Boundaries of the study region are indicated by the black frame in the right-hand-side panel. 

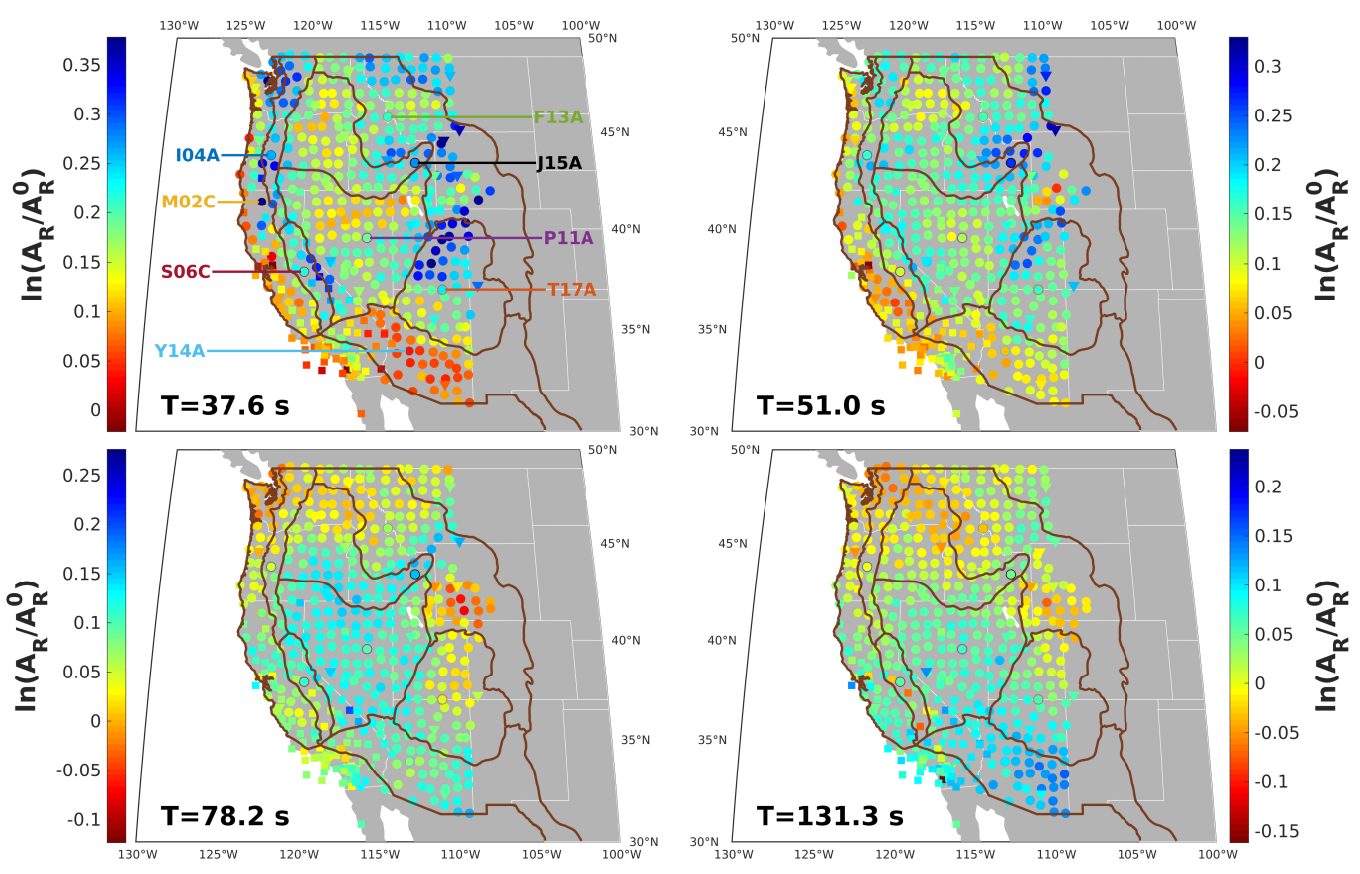

Figure 2: Examples of maps for fundamental mode Rayleigh wave local amplification at four periods of interest. Periods of interest are displayed in the lower-left corner of each map. Each coloured symbol represents a station, the shape depending on the corresponding seismic network (see Fig. 1). The locations of our eight illustrative stations are indicated for reference. Boundaries of tectonic provinces are represented by solid brown lines. 


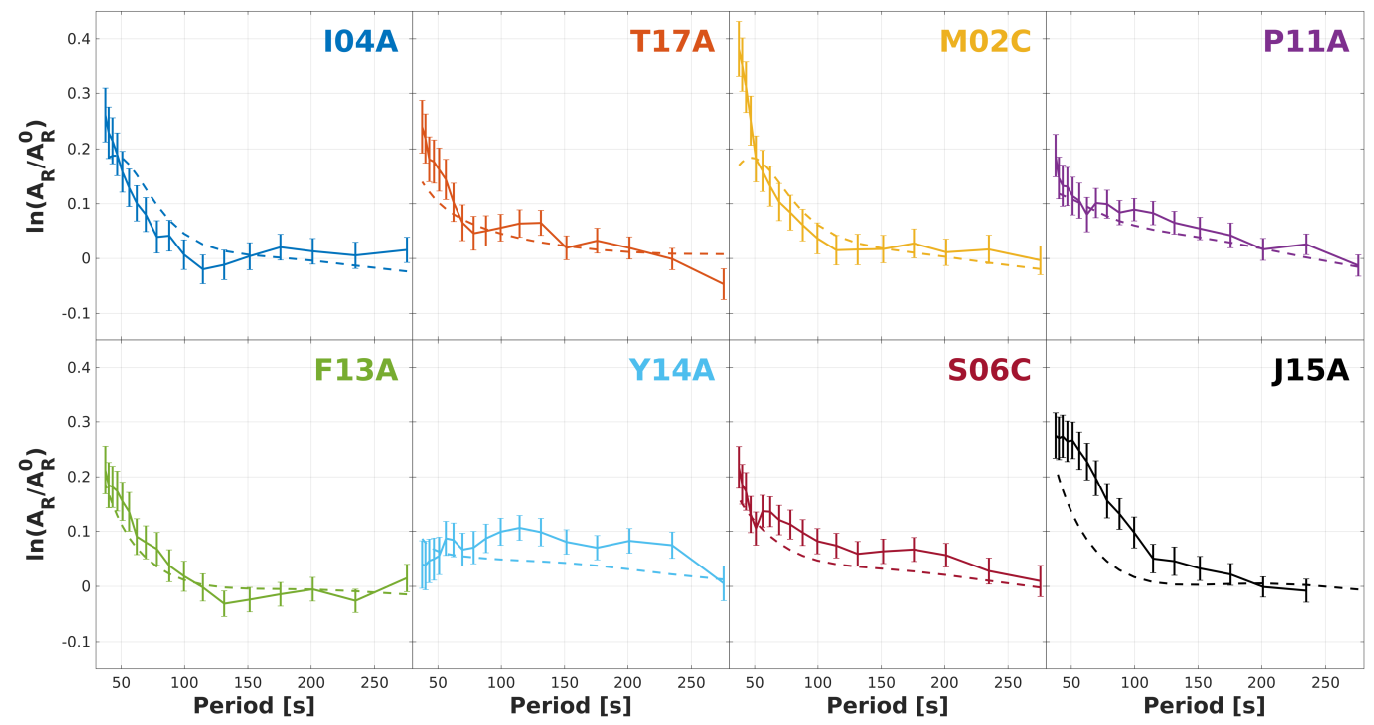

Figure 3: Examples of local amplification curves (solid lines with error bars) measured for our eight illustrative stations located in each of the main tectonic provinces of the western U.S. (see Fig. 1), compared to theoretical curves calculated for 1-D profiles extracted from the 3-D model SGLOBE-rani combined with the crustal model CRUST2.0 (dashed lines). The error bars represent the errors on local amplification measurements calculated using Eq. (6). 
Table 1: Model space for each model parameter considered in the $v_{S}$ inversions. The parameters are expressed as percentual perturbations from the PREM model.

\begin{tabular}{rrr}
\hline Model parameter & Lower bound (\%) & Upper bound (\%) \\
\hline$\frac{\delta v_{S}}{v_{S}}$ in the crust & -30 & 40 \\
1st mantle spline coefficient & -10 & 5 \\
2nd mantle spline coefficient & -20 & 20 \\
3rd mantle spline coefficient & -20 & 20 \\
4th mantle spline coefficient & -20 & 20 \\
\hline
\end{tabular}




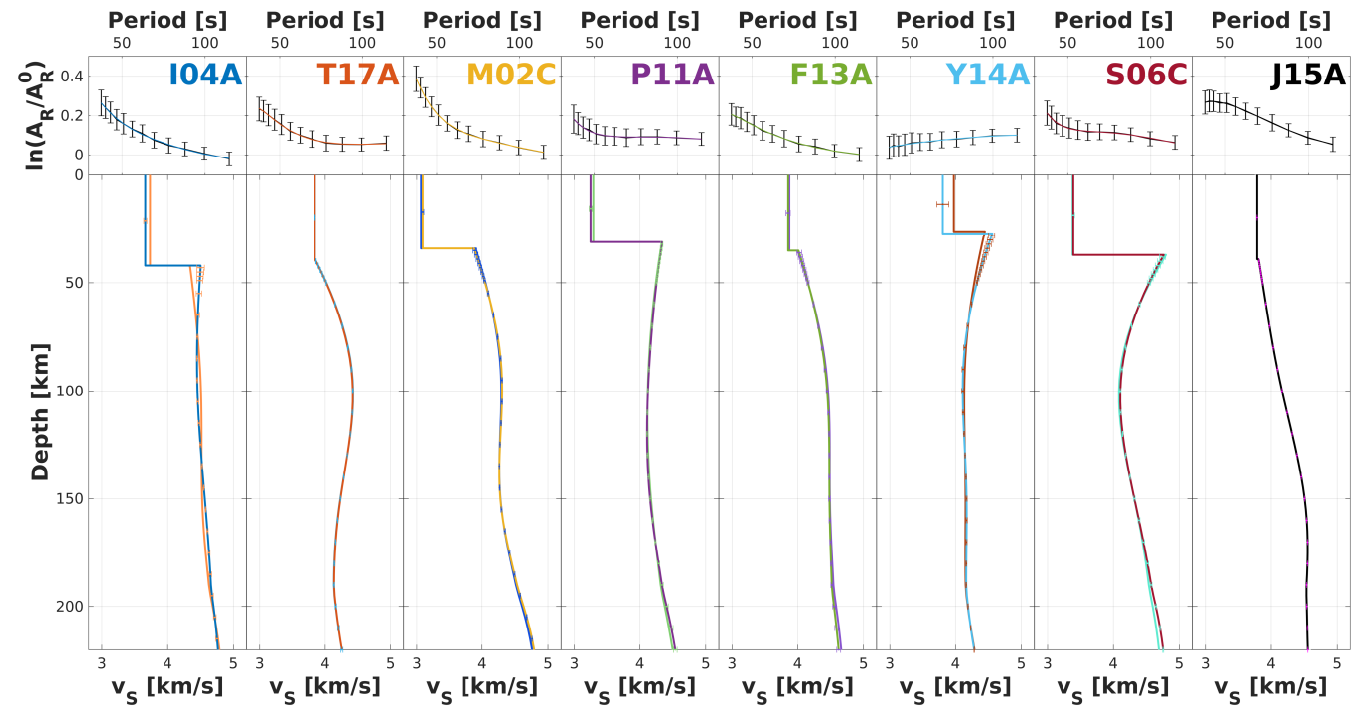

Figure 4: Example of synthetic inversion test. The top panel shows the amplification curves computed for the input, known synthetic model (black lines with black error bars) and for the retrieved output model (coloured line). The bottom panel shows corresponding input and output shear-wave velocity models, with the latter showing the corresponding error bars (see main text for details). 


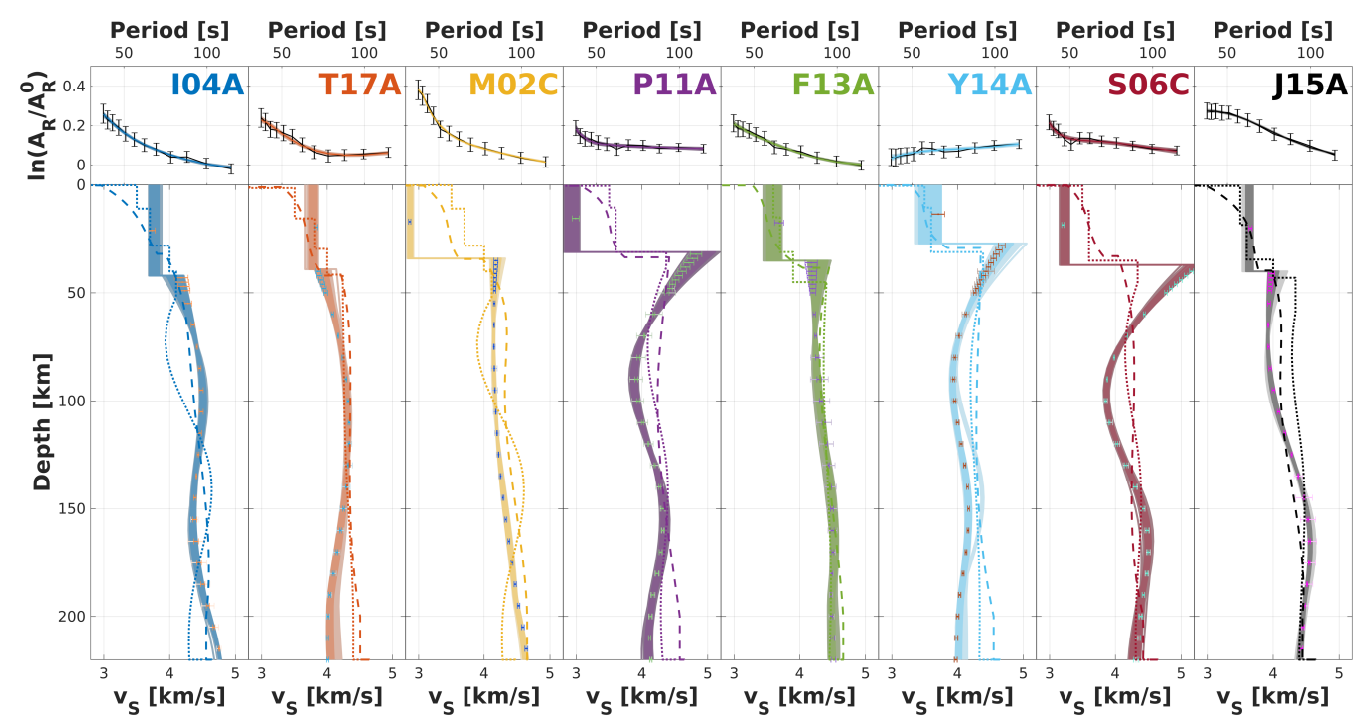

Figure 5: Best-fitting shear-wave velocity profiles (dark solid lines) obtained from real data inversions for eight illustrative stations located in each of the eight major tectonic provinces of the western U.S. (see Fig. 1). The retrieved models are compared to 1-D profiles extracted from the global model SGLOBE-rani (dotted lines) and the regional model of Shen et al. (2013) (dashed lines). Error bars on the velocity profiles correspond to $2.5 \sigma$, where $\sigma$ is the standard deviation computed over all models with a misfit value within $20 \%$ of that of the best-fitting model (lighter solid lines). Error bars calculated for a standard deviation computed over all models (lightest solid lines) with a misfit value within $50 \%$ of that of the best-fitting model are also shown (lighter error bars). They are mostly undistinguishable from the previous set of error bars because the corresponding sets of models are very similar despite the different misfit thresholds. 

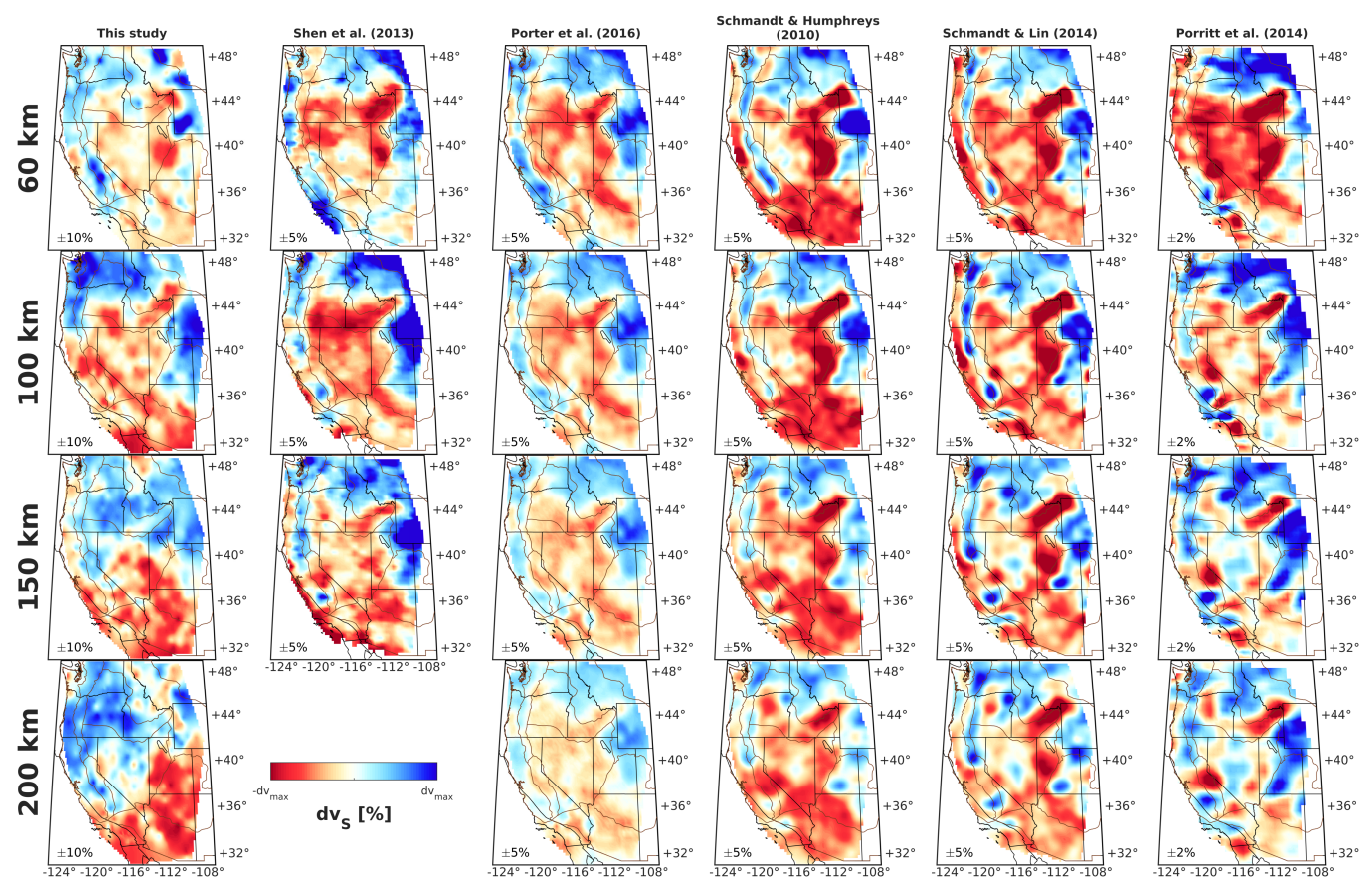

Figure 6: Comparison of the SWUS-amp 3-D shear-wave velocity model (first column) with other recent tomographic models (Shen et al., 2013; Porter et al., 2016; Schmandt and Humphreys, 2010; Schmandt and Lin, 2014; Porritt et al., 2014). The velocity perturbations of the models in the first three columns are expressed with respect to the average at each depth. The models in the last three columns are relative by construction and thus are plotted in their original form. The limits of the colour scale of each model and at each depth are displayed in the bottom left corner of each map. Boundaries of tectonic provinces are represented by solid light brown lines. 

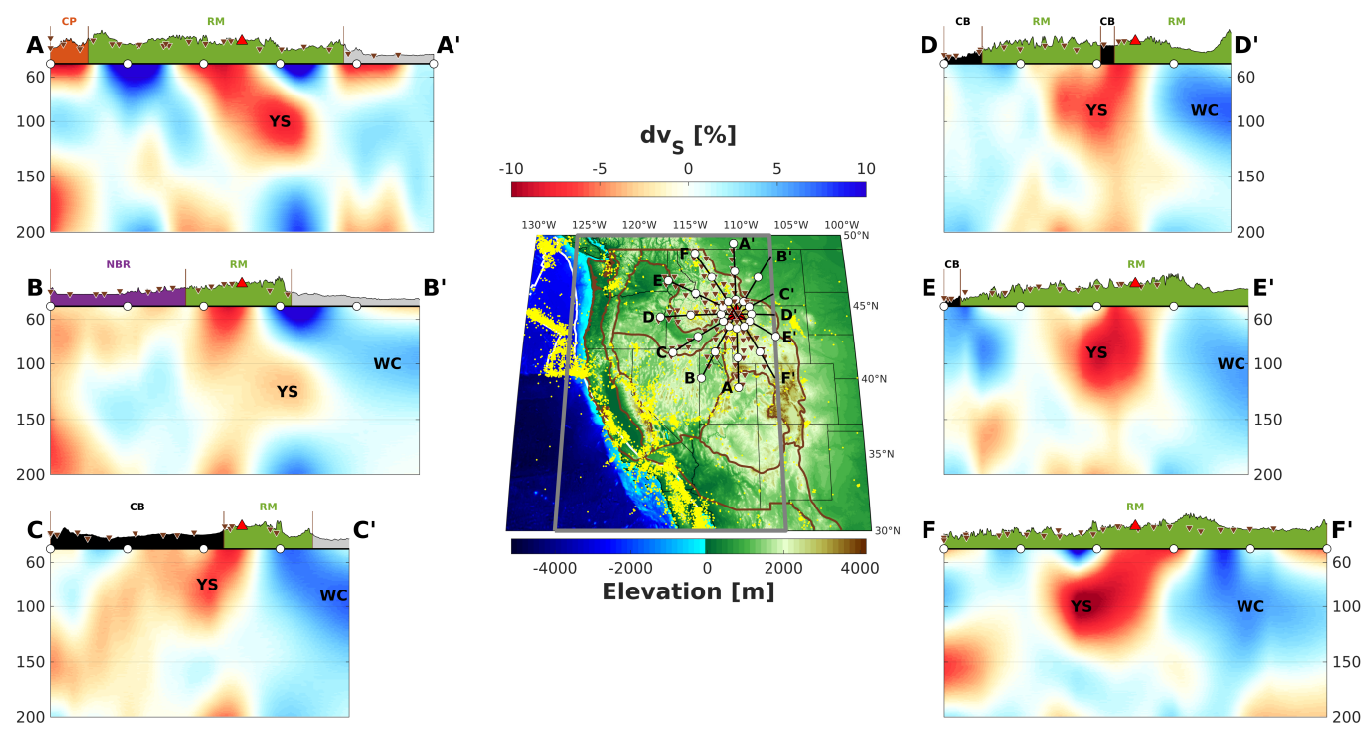

Figure 7: Vertical cross-sections through the SWUS-amp model, centered on the Yellowstone area, expressed as perturbations with respect to the average absolute shear-wave velocity in each cross-section. The locations of the cross-sections are indicated in the central inset map. Circles along each profile track are plotted every $2^{\circ}$. Seismicity (>M4.0) from the ISC bulletin (http://www.isc.ac.uk) is represented by yellow dots. The elevation along each profile is plotted above each cross-section, where the colour fillings match the colours used in Fig. 1 to differentiate the eight major tectonic provinces of the region. Stations within $50 \mathrm{~km}$ of the profile track are represented by triangles. The red triangle denotes Yellowstone's location. 


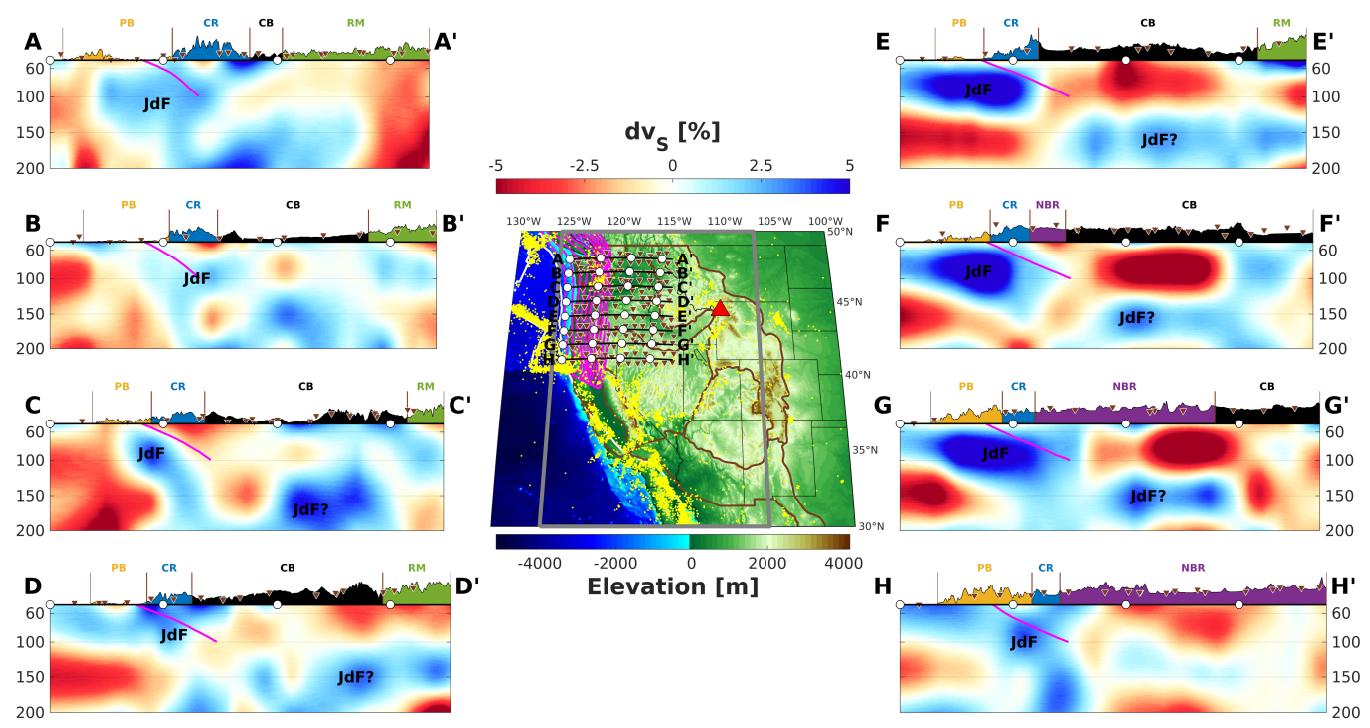

Figure 8: Vertical cross-sections through the SWUS-amp model, focusing on the Cascadia subduction zone, expressed as perturbations with respect to the average absolute velocity in each cross-section. The locations of the cross-sections are indicated in the central inset map. Circles along each profile track are plotted every $2^{\circ}$. Seismicity (>M4.0) from the ISC bulletin (http://www.isc.ac.uk) is represented by yellow dots. The elevation along the profile is plotted above each cross-section, where the colour fillings match the colours used in Fig. 1 to differentiate the eight major tectonic provinces of the region. Stations within $50 \mathrm{~km}$ of the profile track are represented by triangles. Magenta lines represent the Juan de Fuca slab model (https://earthquake.usgs.gov/data/slab/models.php); each line represents a 10-km increment in depth. 


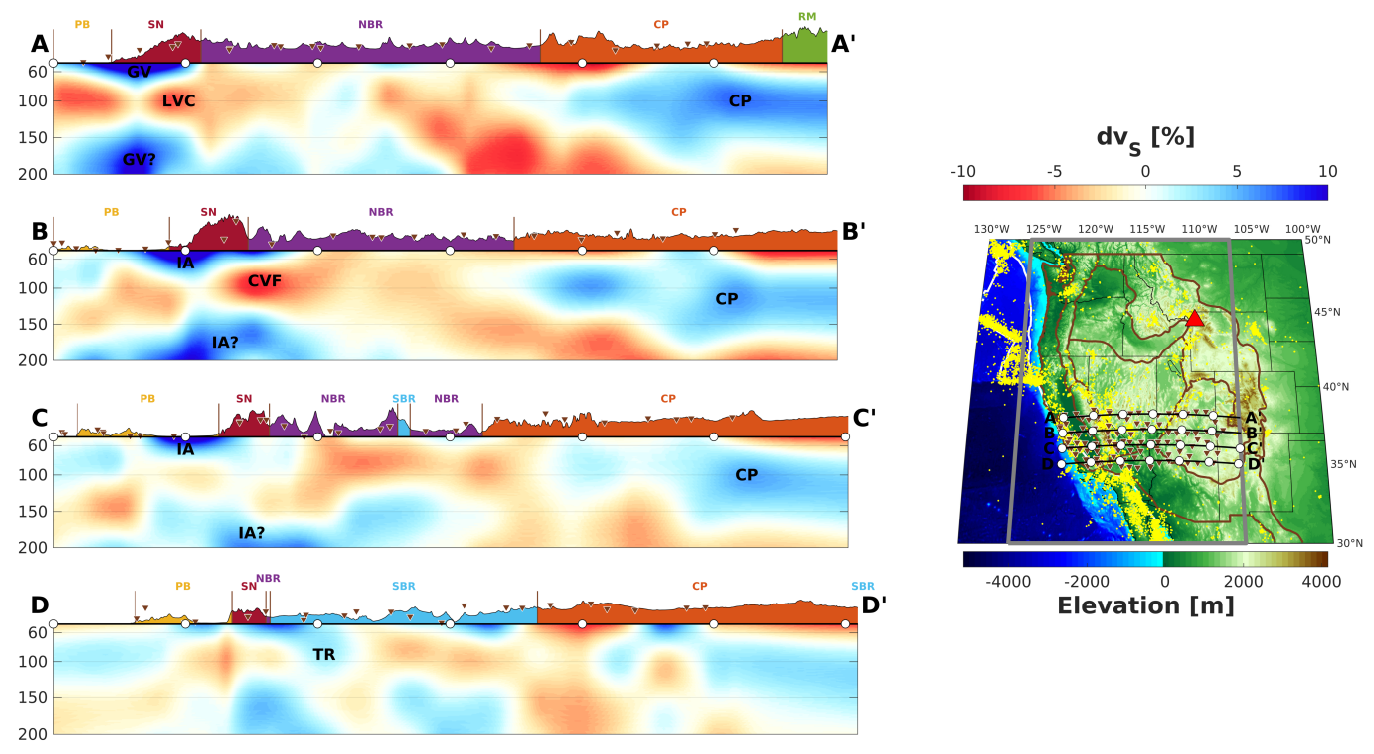

Figure 9: Vertical cross-sections through the SWUS-amp model beneath California, Sierra Nevada, Basin and Range, and Colorado Plateau, expressed as perturbations with respect to the average absolute velocity in each cross-section. The locations of the cross-sections are indicated in the central inset map. Circles along each profile track are plotted every $2^{\circ}$. Seismicity (>M4.0) from the ISC bulletin (http://www.isc.ac.uk) is represented by yellow dots. The elevation along the profile is plotted above each cross-section, where the colour fillings match the colours used in Fig. 1 to differentiate the eight major tectonic provinces of the region. Stations within $50 \mathrm{~km}$ of the profile track are represented by triangles.

\section{Appendix A. Supporting information}

Supplementary information with this article can be found in the online version of this article at http://dx.doi.org/10.xxxx/j.epsl.xxxx.xx.xxx. 
Attanayake, J., Ferreira, A., Berbellini, A., Morelli, A., 2017. Crustal structure beneath Portugal from teleseismic Rayleigh-wave ellipticity. Tectonophysics 712-713, 344-361, doi: 10.1016/j.tecto.2017.06.001.

Atwater, T., 1970. Implications of plate tectonics for the Cenozoic evolution of western North America. Geol. Soc. Am. Bull. 81, 3513-3536, doi: 10.1130/0016-7606(1970)81[3513:IOPTFT]2.0.CO;2.

Bao, X., Dalton, A., Ritsema, J., 2016. Effects of elastic focusing on global models of Rayleigh-wave attenuation. Geophys. J. Int. 207, 1062-1079, doi: $10.1093 /$ gji $/$ ggw322.

Bassin, C., Laske, G., Masters, G., 2000. The current limits of resolution for surface-wave tomography in North America. EOS Trans. AGU 81, F897.

Berbellini, A., Morelli, A., Ferreira, A., 2017. Crustal structure of northern Italy from the ellipticity of Rayleigh waves. Phys. Earth Planet. Inter. 265, 1-14, doi: 10.1016/j.pepi.2016.12.005.

Bird, P., 2003. An updated digital model of plate boundaries. Geochem. Geophys. Geosyst. 4 (3), 1027, doi: 10.1029/2001GC000252.

Buehler, J., Shearer, P., 2014. Anisotropy and $V p / V s$ in the uppermost mantle beneath the western United States from joint analysis of $P n$ and $S n$ phases. J. Geophys. Res. 119, doi: 10.1002/2013JB010559.

Burchfiel, B., Cowen, D., Davis, G., 1992. Tectonic overview of the Cordilleran orogen in the western United States. In: The Geology of North America. Vol. G-3. Geol. Soc. of Am., pp. 407-479.

Chang, S.-J., Ferreira, A., Ritsema, J., van Heijst, H.-J., Woodhouse, J., 2015. Joint inversion for global isotropic and radially anisotropic man- 
tle structure including crustal thickness perturbations. J. Geophys. Res. 120 (6), 4278-4300, doi: 10.1002/2014JB011824.

Christiansen, R., Foulger, G., Evans, J., 2002. Upper-mantle origin of the Yellowstone hotspot. Geol. Soc. Am. Bull. 114 (10), 1245-1256, doi: 10.1130/0016-7606(2002)114;1245:UMOOTY¿2.0.CO;2.

Dalton, C., Bao, X., Ma, Z., 2017. The thermal structure of cratonic lithosphere from global Rayleigh wave attenuation. Earth Planet. Sci. Lett. 457, 250-262, doi: 10.1016/j.epsl.2016.10.014.

Dalton, C., Ekström, G., 2006. Constraints on global maps of phase velocity from surface-wave amplitudes. Geophys. J. Int. 167, 820-826, doi: 10.1111/j.1365-246X.2006.03142.x.

Dave, R., Li, A., 2016. Destruction of the Wyoming craton: Seismic evidence and geodynamic processes. Geology 44, 883-886, doi: 10.1130/G38147.1.

Dziewoński, A., Anderson, D., 1981. Preliminary reference Earth model. Phys. Earth Planet. Inter. 25, 297-357, doi: 10.1016/0031-9201(81)900467.

Eddy, C., Ekström, G., 2014. Local amplification factors of Rayleigh waves in the continental United States observed on the USArray. Earth Planet. Sci. Lett. 402, 50-57, doi: 10.1016/j.epsl.2014.01.013.

Ekström, G., Nettles, M., Dziewoński, A., 2012. The global CMT project 2004-2010: Centroid-moment tensors for 13,017 earthquakes. Phys. Earth Planet. Inter. 200-201, 1-9, doi: 10.1016/j.pepi.2012.04.002. 
Ferreira, A., Woodhouse, J., 2007. Source, path and receiver effects on seismic surface waves. Geophys. J. Int. 168, 109-132, doi: 10.1111/j.1365246X.2006.03092.x.

Gilbert, F., 1970. Excitation of normal modes of the earth by earthquake sources. Geophys. J. R. astr. Soc. 22, 223-226.

Hawley, W., Allen, R., Richards, M., 2016. Tomography reveals buoyant asthenosphere accumulating beneath the Juan de Fuca plate. Science 353 (6306), 1406-1408, doi: 10.1126/science.aad8104.

Huang, H., Lin, F.-C., Schmandt, B., Farrell, J., Smith, R., Tsai, V., 2015. The Yellowstone magmatic system from the mantle plume to the upper crust. Science 6236 (348), 773-776, doi: 10.1126/science.aaa5648.

Humphreys, E., Coblentz, D., 2007. North American dynamics and western U.S. tectonics. Reviews of Geophysics 45, 1-30, doi: 10.1029/2005RG000181.

Humphreys, E., Hager, B., 1990. A kinematic model for the late Cenozoic development of southern California crust and upper mantle. J. Geophys. Res. 95 (B12), 19747-19762, doi: 10.1126/science.aaa5648.

Jiang, C., Schmandt, B., Hansen, S., Dougherty, S., Clayton, R., Farrell, J., Lin, F.-C., 2018. Rayleigh and S wave tomography constraints on subduction termination and lithospheric foundering in central California. Earth Planet. Sci. Lett. 488, 14-26, doi: 10.1016/j.epsl.2018.02.009.

Karlstrom, K., Crow, R., Crossey, L., Coblentz, D., Van Wijk, J., 2008. Model for tectonically driven incision of the younger than $6 \mathrm{Ma}$ Grand Canyon. Geology 36, 835-838, doi: 10.1130/G25032A.1. 
Kelbert, A., Egbert, G., deGroot-Hedlin, C., 2012. Crust and upper mantle electrical conductivity beneath the Yellowstone Hotspot Track. Geology 40, 447-450, doi: 10.1130/G32655.1.

Komatitsch, D., Tromp, J., 2002. Spectral-element simulations of global seismic wave propagation - II. Three-dimensional models, oceans, rotation and self-gravitation. Geophys. J. Int. 150 (1), 303-318, doi: 10.1046/j.1365246X.2002.01716.x.

Laske, G., Masters, G., Ma, Z., Pasyanos, M., 2013. Update on CRUST1.0 - A 1-degree global model of Earth's crust. Abstract EGU2013-2658, presented at 2013 EGU General Assembly, Vienna, Austria, 7-12 apr.

Levander, A., Schmandt, B., Miller, M., Liu, K., Karlstrom, K., Crow, R., Lee, C.-T. A., Humphreys, E., 2011. Continuing Colorado plateau uplift by delamination-style convective lithospheric downwelling. Nature 472, 461465, doi: 10.1130/G32655.1.

Lin, F.-C., Tsai, V., Ritzwoller, M., 2012. The local amplification of surface waves: A new observable to constrain elastic velocities, density, and anelastic attenuation. J. Geophys. Res. 117 (B06302), doi: 10.1029/2012JB009208.

Liu, K., Levander, A., Niu, F., Miller, M., 2011. Imaging crustal and upper mantle structure beneath the Colorado Plateau using finite frequency Rayleigh wave tomography. Geochem. Geophys. Geosyst. 12 (Q07001), doi: 10.1029/2011GC003611.

Maupin, V., 2017. 3-D sensitivity kernels of the Rayleigh wave ellipticity. Geophys. J. Int. 211, 107-119, doi: 10.1093/gji/ggx294. 
Nelson, P., Grand, S., 2018. Lower-mantle plume beneath the Yellowstone hotspot revealed by core waves. Nat. Geosci. 11, 280-284, doi: 10.1038/s41561-018-0075-y.

Obrebski, M., Allen, R., Pollitz, F., Hung, S.-H., 2011. Lithosphereasthenosphere interaction beneath the Western United States from the joint inversion of body-wave traveltimes and surface-wave phase velocities. Geophys. J. Int. 185, 1003-1021, doi: 10.1111/j.1365-246X.2011.04990.x.

Obrebski, M., Allen, R., Xue, M., Hung, S.-H., 2010. Slab-plume interaction beneath the Pacific Northwest. Geophys. Res. Lett. 37, L14305, doi: 10.1029/2010gl043489.

Parisi, L., Ferreira, A., 2016. Empirical assessment of the validity limits of the surface wave full ray theory using realistic 3-D Earth models. Geophys. J. Int. 205, 146-159, doi: 10.1093/gji/ggw005.

Porritt, R., Allen, R., Pollitz, F., 2014. Seismic imaging east of the Rocky Mountains with USArray. Earth Planet. Sci. Lett. 402, 16-25, doi: 10.1016/j.epsl.2013.10.034.

Porter, R., Liu, Y., Holt, W., 2016. Lithospheric records of orogeny within the continental U.S. Geophys. Res. Lett. 43 (1), 144-153, doi: 10.1002/2015GL066950.

Rawlinson, N., Pozgay, S., Fishwick, S., 2010. Seismic tomography: A window into deep Earth. Phys. Earth Planet. Inter. 178, 101-135, doi: 10.1016/j.pepi.2009.10.002.

Sambridge, M., 1999. Geophysical inversion with a neighbourhood algorithm - I. Searching a parameter space. Geophys. J. Int. 138, 479-494, doi: 10.1046/j.1365-246X.1999.00876.x. 
Schmandt, B., Humphreys, E., 2010. Complex subdution and smallscale convection revealed by body-wave tomography of the western United States upper mantle. Earth Planet. Sci. Lett. 297, 435-445, doi: 10.1016/j.epsl.2010.06.047.

Schmandt, B., Lin, F.-C., 2014. P and S wave tomography of the mantle beneath the United States. Geophys. Res. Lett. 41 (18), 6342-6349, doi: 10.1002/2014GL061231.

Shen, W., Ritzwoller, M., 2016. Crustal and uppermost mantle structure beneath the United States. J. Geophys. Res. 121 (6), 4306-4342, doi: 10.1002/2016JB012887.

Shen, W., Ritzwoller, M., Schulte-Pelkum, V., 2013. A 3-D model of the crust and uppermost mantle beneath the Central and Western US by joint inversion of receiver functions and surface wave dispersion. J. Geophys. Res. 118, 262-276, doi: 10.1029/2012JB009602.

Tharimena, S., Rychert, C., Harmon, N., 2017. A unified continental thickness from seismology and diamonds suggests a melt-defined plate. Science 357 (6351), 580-583, doi: 10.1126/science.aan0741.

Torsvik, T. H., Smethurst, M. A., Burke, K., Steinberger, B., 2006. Large igneous provinces generated from the margins of the large low-velocity provinces in the deep mantle. Geophys. J. Int. 167, 1447-1460, doi: 10.1111/j.1365-246X.2006.03158.x.

van Heijst, H.-J., Woodhouse, J., 1997. Measuring surface-wave overtone phase velocities using a mode-branch technique. Geophys. J. Int. 131, 209230, doi: j.1365-246X.1997.tb01217.x. 
Yuan, H., Dueker, K., 2005. Upper mantle tomographic $V_{p}$ and $V_{s}$ images of the Rocky Mountains in Wyoming, Colorado and New Mexico: Evidence for a thick heterogeneous chemical lithosphere. Geophys. Monogr. 154, 329-345, doi: 10.1029/154GM25.

Zandt, G., Gilbert, H., Owens, T., Ducea, M., Saleeby, J., Jones, C., 2004. Active foundering of a continental arc root beneath the southern Sierra Nevada in California. Nature 431 (2), 41-46, doi: 10.1038/nature02847.

Zhou, Q., Hu, J., Liu, L., Chaparro, T., Stegman, D. R., Faccenda, M., 2018a. Western U.S. seismic anisotropy revealing complex mantle dynamics. Earth Planet. Sci. Lett. 500, 156-167, doi: 10.1016/j.epsl.2018.08.015.

Zhou, Q., Liu, L., Hu, J., 2018b. Western U.S. volcanism due to intruding oceanic mantle driven by ancient Farallon slabs. Nat. Geosci. 11, 70-76, doi: 10.1038/s41561-017-0035-y. 